\title{
Association between breastfeeding during infancy and white matter microstructure in early childhood
}

\author{
Preeti Kar ${ }^{\mathrm{a}, \mathrm{b}}$, Jess E. Reynolds ${ }^{\mathrm{a}, \mathrm{b}, \mathrm{c}}$, Melody N. Grohs ${ }^{\mathrm{a}, \mathrm{b}}$, Rhonda C. Bell ${ }^{\mathrm{e}}$, Megan Jarman ${ }^{\mathrm{e}}$, \\ Deborah Dewey ${ }^{\mathrm{a}, \mathrm{b}, \mathrm{d}, \mathrm{f}}$, Catherine Lebel ${ }^{\mathrm{a}, \mathrm{b}, \mathrm{c}, *}$
}

${ }^{a}$ Alberta Children's Hospital Research Institute, Canada

${ }^{\mathrm{b}}$ Hotchkiss Brain Institute, University of Calgary, Canada

${ }^{\mathrm{c}}$ Departments of Radiology, University of Calgary, Canada

${ }^{\mathrm{d}}$ Department of Pediatrics, University of Calgary, Canada

e Department of Agricultural, Food \& Nutritional Science, University of Alberta, Canada

${ }^{\mathrm{f}}$ Department of Community Health Sciences, University of Calgary, Canada

\section{A R T I C L E I N F O}

\section{Keywords:}

Magnetic resonance imaging

Diffusion tensor imaging

Preschool

Brain

Nutrition

APrON

\begin{abstract}
A B S T R A C T
Introduction: Associations between breastfeeding and brain development, in the context of child, perinatal, and sociodemographic variables, remain unclear. This study investigated whether exclusive breastfeeding for the first 6 months and total duration of breastfeeding were associated with brain white matter microstructure in young children.

Methods: This study included 85 typically developing children (42 males) born to 83 mothers that were predominantly white, highly educated, and in high income households. Children underwent their first diffusion tensor imaging scan between ages 2.34 and 6.97 years; some children returned multiple times, providing a total of 331 datasets. Feeding information was collected from mothers at 3, 6, and 12 months postpartum and at their child's scan to calculate breastfeeding status at 6 months (exclusive or not) as well as total duration of any breastfeeding. Linear regression was used to investigate associations between breastfeeding exclusivity/duration and fractional anisotropy (FA) for the whole brain and 10 individual white matter tracts.
\end{abstract}

Results: Breastfeeding exclusivity and duration were associated with global and regional white matter microstructure, even after controlling for perinatal and sociodemographic factors. Greater exclusivity was associated with higher FA in females and lower FA in males.

Conclusions: These findings suggest white matter differences associated with breastfeeding that differ by sex. These may stem from different trajectories in white matter development between males and females in early childhood and suggest possible long-term white matter differences associated with breastfeeding.

\section{Introduction}

Breastfeeding is associated with positive health outcomes in children (Kramer, 2010) along with health and economic advantages for mothers (Martin et al., 2016; McInerny, 2014). Accordingly, the World Health Organization (WHO) recommends exclusive breastfeeding for the first 6 months of life followed by continued breastfeeding with appropriate complementary foods up to 2 years of age or beyond (WHO, 2003). There is some evidence that greater exclusivity in the first 6 months and longer breastfeeding are associated with cognitive advantages for children and adolescents (Anderson et al., 1999; Bernard et al., 2013; Kramer et al., 2008), possibly stemming from the nutritional composition of breastmilk and/or caregiver interactions during breastfeeding promoting cognitive and brain development (Guesnet and Alessandri, 2011; Krol and Grossmann, 2018).

Neuroimaging offers insight into the brain structures that have been associated with cognitive abilities; however, only a few magnetic res-

Abbreviations: (MRI), magnetic resonance imaging; (FA), fractional anisotropy; (DTI), diffusion tensor imaging; (APrON), Alberta Pregnancy Outcomes and

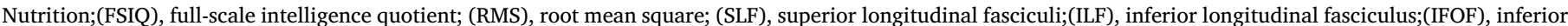
fronto-occipital fasciculus; (UF), uncinate fasciculus; (MD), mean diffusivity; (EBF), exclusively breastfed;(nEBF), not exclusively breastfed.

* Corresponding author at: Alberta Children's Hospital Research Institute, 28 Oki Drive NW, Calgary, Alberta, T3B 6A8, Canada.

E-mail addresses: preeti.kar@ucalgary.ca (P. Kar), jessica.reynolds@ucalgary.ca (J.E. Reynolds), melody.grohs@ucalgary.ca (M.N. Grohs), bellr@ualberta.ca (R.C. Bell), m.jarman@aston.ac.uk (M. Jarman), dmdewey@ucalgary.ca (D. Dewey), clebel@ucalgary.ca (C. Lebel). 
onance imaging (MRI) studies have probed the underlying associations between brain structure and breastfeeding. These studies highlight the role of white matter, suggesting that exclusivity and duration of breastfeeding are associated with alterations to myelin water fraction (Deoni et al., 2018; Deoni et al., 2013), anisotropy and diffusivity (Bauer et al., 2020; Blesa et al., 2019; Ou et al., 2014), and total white matter volume (Isaacs et al., 2010). Specifically, greater myelination of frontal-temporal white matter in full-term infants and children (Deoni et al., 2018; Deoni et al., 2013), as well as higher fractional anisotropy (FA; a measure associated with myelination, axonal packing, and fiber coherence) in frontal-parietal white matter of preterm infants (Blesa et al., 2019) and frontal-temporal white matter of schoolaged children (Bauer et al., 2020) have all been associated with breastfeeding. Other studies have reported null findings: white matter volume did not differ between breastfed and non-breastfed full-term adolescents (Luby et al., 2016), nor was it associated with duration of breastfeeding in school-aged children (Bauer et al., 2020) or dosage of breast milk in preterm infants scanned at term-equivalent age (Belfort et al., 2016; Blesa et al., 2019) and at 7 years of age (Belfort et al., 2016). Furthermore, only some studies have examined sex differences; one showed that the percentage of expressed maternal breastmilk in preterm-born infants' diets was associated with white matter volume in males but not females during adolescence (Isaacs et al., 2010), while the other showed that breastfed males had significantly higher whole brain FA than formula-fed males aged 7-8 years, with no group differences in females (Ou et al., 2014). Given that males and females show different trajectories of brain development (Reynolds et al., 2019), it is critical to disentangle the potentially complex associations among white matter and breastfeeding, in the context of child age and sex, in large, longitudinal prospective studies.

It is also important to further investigate the role of perinatal and sociodemographic variables in breastfeeding-brain structure associations. Patterns of breastfeeding vary with maternal education and intelligence, child's gestational age and birthweight, as well as socioeconomic status (Der et al., 2006; Jessri et al., 2013) and importantly, these variables are all associated with neurodevelopment (Batalle et al., 2017; Brito and Noble, 2014; Lugo-gil et al., 2008; Noble et al., 2015; Ronfani et al., 2015). Some studies that accounted for confounding variables such as maternal intelligence, education, or household income observed attenuated associations between breastfeeding and cognitive abilities (GibsonDavis and Brooks-Gunn, 2006; Horwood et al., 2001; Jacobson et al., 1999; McCrory and Murray, 2013). Thus, it is critical to control for perinatal and sociodemographic factors when investigating associations between neurodevelopment and breastfeeding in pediatric populations.

Of particular interest is understanding whether breastfeeding is associated with brain development during the early childhood period, a time of extensive changes to the brain and rapid cognitive, behavioral, and emotional development (Deoni et al., 2012; Hermoye et al., 2006; Pfefferbaum et al., 1994). The objective of this study was to assess the association between white matter microstructure in young children (27 years) and breastfeeding exclusivity status at 6 months of age, as well as total duration of any breastfeeding. We used diffusion tensor imaging (DTI) to assess tissue microstructure as this technique is sensitive to myelination, axonal packing, and fiber coherence. Given the diverse and widespread nature of previous white matter alterations associated with breastfeeding (Bauer et al., 2020; Belfort et al., 2016; Blesa et al., 2019; Deoni et al., 2018; Deoni et al., 2013; Ou et al., 2014), we investigated white matter tracts across the brain, as well as the whole brain average, accounting for age-related changes and sex differences in a homogenous sample of children (i.e., predominantly white, highly educated, and high income households) while controlling for perinatal and sociodemographic variables. Based on the literature showing global and regional differences in myelin water fraction and white matter anisotropy (Bauer et al., 2020; Blesa et al., 2019; Deoni et al., 2018; Deoni et al., 2013; Ou et al., 2014), we hypothesized that exclusive breastfeeding for the first 6 months and longer durations of breastfeeding would be asso- ciated with higher FA in the whole brain and in individual white matter tracts.

\section{Methods}

\subsection{Participants}

This study included a convenience sample of 85 typically-developing children (42 males; 2 sets of non-twin siblings) and their 83 mothers. Participants were recruited from Calgary and surrounding areas $(n=8)$ as well as from the ongoing Alberta Pregnancy Outcomes and Nutrition (APrON) study ( $n=77$ ), a longitudinal cohort study of pregnant women (Kaplan et al., 2014). Inclusion criteria were full-term birth ( $>37$ weeks' gestation), birthweight $>2500$ grams, living in the Calgary area, and ability to speak English as a primary language. Exclusion criteria were contraindications to MRI (e.g. braces, metal implants), brain injury, or a diagnosis of genetic or developmental disorders that impact cognitive and/or motor function (e.g. autism spectrum disorder). At the time of the first MRI scan, children were between 2.34 and 6.97 years (3.88 \pm 0.94 years); families were invited to return approximately every 6 months for a follow-up scan, though not everyone returned for each visit. This study included a total of 331 datasets from the 85 participants, with an average time of $7.52 \pm 4.43$ months between visits. Data analyzed here includes 19 children with one scan, 15 with two scans, 4 with three scans, 11 with four scans, 16 with five scans, 11 with six scans, 7 with seven scans, 1 with eleven scans, and 1 with twenty scans. Written parental/guardian informed consent and verbal child assent were obtained for each subject at each scan. The University of Calgary Conjoint Health Research Ethics Board (CHREB) approved this study (REB18-0647).

\subsection{Data collection of breastfeeding patterns}

For participants recruited from the APrON study, prospective data was acquired from the mothers about breastfeeding when children were 3 months, 6 months, and 12 months of age. Mothers were asked about breastfeeding and formula feeding patterns, including child's age when they started and stopped, along with frequency of feeding, as outlined in Fig. 1. The questionnaire also asked when and if other liquids (nonbreast milk and non-milk liquids) or solid foods were introduced and their frequency of consumption. For all participants, mothers were asked again via a questionnaire about the child's age when they started and stopped breastfeeding and formula feeding during the appointment for their child's MRI scan.

\subsection{Data collection of child, perinatal and sociodemographic covariates}

At the first MRI scan, information about mothers (age at delivery, ethnicity) and children (age at scan, sex, gestational age at birth, birthweight) was obtained as a part of questionnaires. To assess socioeconomic status, information was collected about household income in the past year as a categorical variable $(<\$ 25,000 ; \$ 25,000-49,999$; $\$ 50,000-74,999 ; \quad \$ 75,000-99,999 ; \quad \$ 100,000-124,999 ; \quad \$ 125,000$ $149,999 ; \$ 150,000-174,999 ;>\$ 175,000)$ and maternal years of post-secondary education as a continuous variable. A subset of children $(n=73)$ completed the Wechsler Preschool and Primary Scale of Intelligence-Fourth Edition (WPPSI-IV)(Wechsler, 2012) within 24 months of their MRI scan, which provided a full-scale intelligence quotient (FSIQ).

\subsection{Neuroimaging data acquisition}

MRI scanning took place at the Alberta Children's Hospital on the research-dedicated GE 3T MR750w system with a 32-channel head coil. Children were not sedated for scanning, but were prepared using at-home materials and/or mock scanner training (Thieba et al., 2018), 


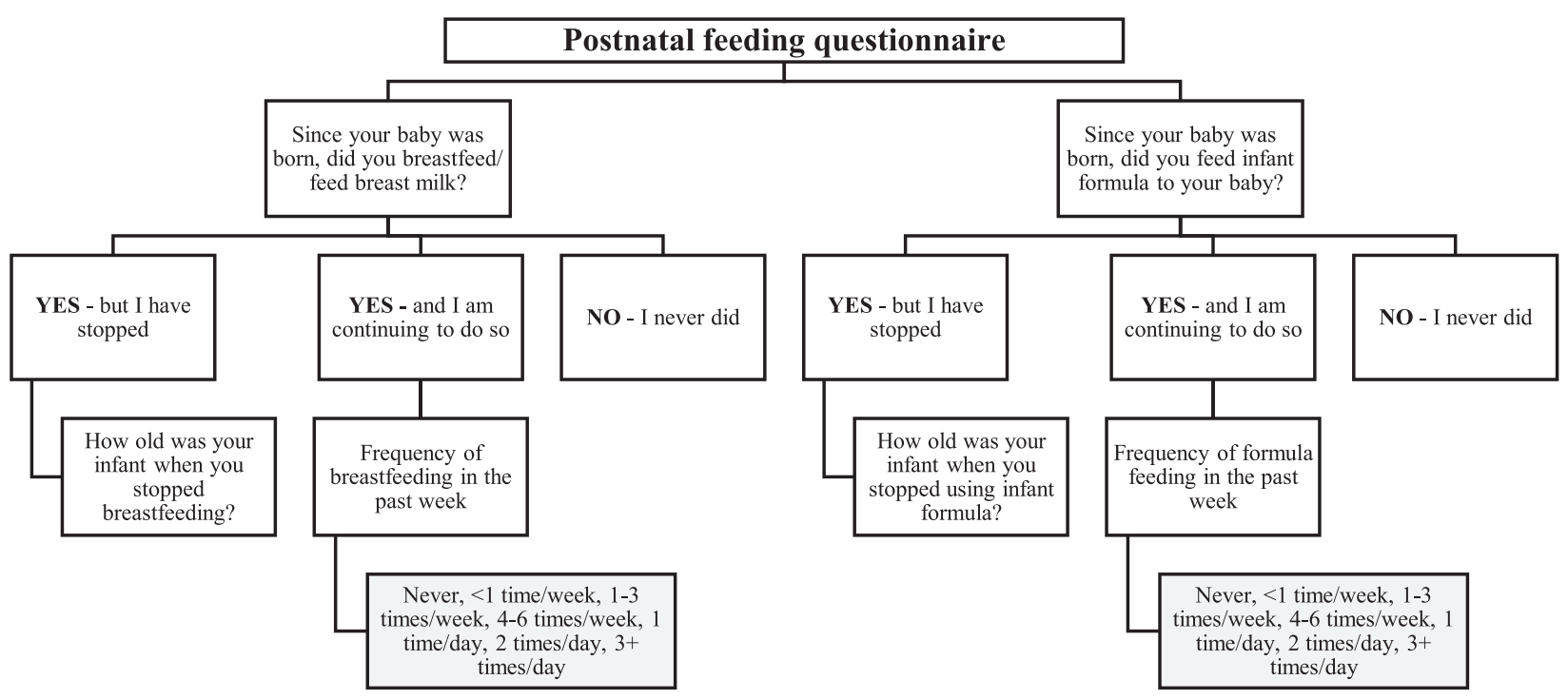

Fig. 1. Infant feeding questionnaire included in the Alberta Pregnancy Outcomes and Nutrition (APrON) study. Participants were asked at 3, 6, and 12 months about feeding patterns for breastmilk and infant formula.

including a book describing the scanning procedures as a rocket ship adventure (https://www.lulu.com/content/e-book/pluto-and-the-mrirocket-ship-adventure/16524875? page=1\&pageSize=41\&pageSize=4). Whole-brain diffusion weighted images were acquired in 4:03 min using a single shot spin echo echo-planar imaging sequence with: $1.6 \times 1.6 \times 2.2 \mathrm{~mm}$ resolution (resampled to $0.78 \times 0.78 \times 2.2 \mathrm{~mm}$ on the scanner), $\mathrm{TR}=6750 \mathrm{~ms}$; TE $=79 \mathrm{~ms}, 30$ gradient encoding directions at $b=750 \mathrm{~s} / \mathrm{mm}^{2}$, and five interleaved images without diffusion encoding at $b=0 \mathrm{~s} / \mathrm{mm}^{2}$. Diffusion MRI was acquired as part of a longer neuroimaging protocol (Reynolds et al., 2020).

\subsection{Neuroimaging data processing}

DTI data was qualitatively evaluated through visual inspection to remove volumes with artifacts or motion corruption, as per our previous methods (Reynolds et al., 2019; Walton et al., 2018). All children had $\geq 18$ diffusion weighted volumes $(28 \pm 3)$ and $\geq 2$ non-diffusion weighted volumes $(5 \pm 0)$ remaining after removal of motion-corrupted data. To quantitatively assess DTI data, the eddy tool from the FSL (6.0.1) Diffusion Toolbox (5.0) (Andersson and Sotiropoulos, 2016) was used to evaluate eddy current-related artifacts throughout the scan. This is calculated as the restricted root mean square (RMS) displacement of each voxel compared to the previous volume for all voxels in the brain. Restricted RMS displacement in the sample was between 0.09 and 1.82 $(0.36 \pm 0.26)$ and this correlated with the number of remaining diffusion weighted volumes $(r=-0.73)$ and non-diffusion weighted volumes $(r=-0.45)$.

Data was preprocessed using ExploreDTI (V4.8.6), including corrections for signal drift, Gibbs ringing, subject motion, and eddy current distortions (Leemans et al., 2009). Semi-automated deterministic streamline tractography was used to delineate 10 major white matter tracts: the corpus callosum (genu, body, splenium), fornix, cingulum, pyramidal tract, superior and inferior longitudinal fasciculi (SLF, ILF), inferior fronto-occipital fasciculus (IFOF), and uncinate fasciculus (UF) (Lebel et al., 2012; Lebel et al., 2008; Reynolds et al., 2019). Detailed descriptions of region of interest selection for tracking procedures can be found at https://doi.org/10.6084/m9.figshare.7603271 (Reynolds et al., 2020). The minimum FA threshold was set to 0.20 to initiate and continue tracking, and angle threshold set to $30^{\circ}$ to minimize spurious fibers (Lebel et al., 2008; Reynolds et al., 2019). Tracts were manually quality checked and additional exclusion regions of interest were drawn as required. Average FA was extracted for all white matter fibers in the whole brain as well as for each of the 10 major tracts. For every tract except the corpus callosum (genu, body, splenium) and the fornix, FA values were calculated separately for left and right hemispheres and subsequently averaged. As additional measures of white matter microstructure, mean, axial, and radial diffusivity (MD, $\mathrm{AD}, \mathrm{RD}$ ) were also extracted for all white matter tracts (see supplementary Methods).

\subsection{Statistical analysis}

All statistical analyses were completed using Statistical Package for the Social Sciences (SPSS; Version 25).

\subsubsection{Demographics}

The Shapiro-Wilk test was used to test all variables for normality, which showed that the following variables were not normally distributed: age at scan, gestational age at birth, age at delivery, postsecondary education, total duration of breastfeeding, motion variables. Thus, we used a Mann-Whitney U test to compare these variables between breastfeeding exclusivity groups (groups described in next section); effect size calculated using Cohen's d. For the remaining variables (birthweight, FSIQ) that were normally distributed, we used a t-test when comparing between breastfeeding exclusivity groups; effect size was calculated using Cohen's d. Chi-squared tests were used to test for group differences for child's sex, maternal ethnicity, and family income; effect size was calculated using Cramer's V. The Shapiro-Wilk test determined that total duration of breastfeeding was not normally distributed. Thus, Spearman correlations were used to test for associations between total duration of any breastfeeding with child's age at scan, gestational age, birthweight, FSIQ, maternal years of post-secondary education, maternal age at delivery, and all motion variables. A univariate test of variance was used to test for associations between total duration of any breastfeeding and child's sex, maternal ethnicity, and family income; effect size was calculated using partial eta squared. These analyses were completed for the entire sample $(n=85)$ and for the subset of participants with FSIQ scores $(n=73)$.

\subsubsection{Breastfeeding exclusivity analysis}

Children were divided into groups based on the information provided by mothers about feeding patterns at the 3-months and 6-months of age. Exclusive breastfeeding (EBF) was defined as feeding breastmilk with no non-breastmilk milk liquids (e.g., formula, cow's milk) for the 
first 6 months of life; this group consisted of 50 children (200 datasets). Children who were not exclusively breastfed (nEBF) for the first 6 months of life received either a mix of breastmilk and formula $(n=29$; 108 datasets) or were predominantly formula-fed ( $n=6 ; 23$ datasets). A general linear mixed effects analysis was used to test group differences (EBF vs. nEBF) for FA of the whole brain and individual tracts. For this analysis, the primary model included breastfeeding exclusivity group, child's sex, child's age at scan, as well as all possible group-sex-age interactions (sex*age, sex* group, age* group, group*sex*age); subject was included as a random factor. Interactions that were not significant were removed and the model was re-run. Where sex interactions were significant, post-hoc tests were run separately in males and in females to better understand sex differences in the association between breastfeeding exclusivity group and FA. Percent difference of mean FA was calculated using the formula $\left(\mathrm{FA}_{\mathrm{nEBF}}-\mathrm{FA}_{\mathrm{EBF}}\right) / \mathrm{FA}_{\mathrm{nEBF}}$. Differences were calculated for significant sex-by-group interactions (EBF vs. nEBF males and EBF vs. nEBF females) as well as for significant age-by-group interactions (EBF vs. nEBF at 3 years of age and EBF vs. nEBF at 7 years of age). Significance level was set at $p<0.05$; false discovery rate was used to correct for 22 multiple comparisons ( 2 analyses - exclusivity and duration - for each of the 10 tracts and the whole brain). Identical analyses were conducted with $\mathrm{MD}, \mathrm{AD}$, and $\mathrm{RD}$ (see supplementary Methods).

\subsubsection{Breastfeeding duration analysis}

Total duration of any breastfeeding was available for 82 children (327 datasets) and ranged from 0.008 years to 4 years ( $1.2 \pm 0.7$ years; all children were breastfed at least once). A general linear mixed effects model was used to test associations between total duration of any breastfeeding and FA in the whole brain and individual tracts. This analysis tested breastfeeding as a continuous variable, with the primary model including duration of breastfeeding, child's sex, child's age at scan, as well as all duration-sex-age interactions (sex*age, sex*duration, age*duration, and duration*sex*age); subject was included as a random factor. Interactions that were not significant were removed and the model was re-run. Significance level was set at $p<0.05$; false discovery rate was used to correct for 22 multiple comparisons ( 2 analyses - exclusivity and duration - for each of the 10 tracts and the whole brain). Identical analyses were conducted with $\mathrm{MD}, \mathrm{AD}$, and $\mathrm{RD}$ (see supplementary Methods).

\subsubsection{Covariate analyses}

For both breastfeeding exclusivity group and breastfeeding duration analyses, the following variables were added to the primary statistical model: child's gestational age, child's birthweight, maternal years of post-secondary education, maternal age at delivery, maternal ethnicity, and family income. Covariates were included based on known associations with patterns of breastfeeding (Der et al., 2006; Gibbs and Forste, 2014; Jain et al., 2002; Jessri et al., 2013; Walfisch et al., 2013) and/or neurodevelopmental outcomes (Batalle et al., 2017; Brito and Noble, 2014; Lugo-gil et al., 2008; Noble et al., 2015; Ronfani et al., 2015). Two other analyses were also run. First, we added child's FSIQ to the primary statistical model for those children who had FSIQ scores ( $n=73 ; 296$ datasets). Second, we added the restricted RMS displacement of voxels between volumes to the primary statistical model to account for estimated motion throughout the scan.

\subsubsection{Within-subjects analysis}

To test within-subject effects, individual regression slopes for FA across ages were calculated for the whole brain and each individual tract in participants with at least two scans. A univariate test of covariance was run to compare slopes for FA in the whole brain and each tract between breastfeeding groups (EBF $n=40$; $\mathrm{nEBF} n=26$ ); the model included group, sex, and a sex-by-group interaction. A univariate test of covariance was also run to investigate the association between slopes for FA in the whole brain and each tract with total duration of breast- feeding ( $n=65)$; the model included duration, sex, and a sex-by-duration interaction.

\subsection{Data availability}

Neuroimaging data is publicly available on the Open Science Framework here: https://osf.io/axz5r/ (Reynolds et al., 2020). Alberta Pregnant Outcomes and Nutrition (APrON) cohort breastfeeding data is available on SAGE: https://dataverse.library.ualberta.ca/dataverse/ SAGE.

\section{Results}

\subsection{Demographics}

The EBF group had more females $(p=0.003)$, higher gestational age at birth $(p=0.028)$, and were breastfed for longer durations $(p<0.001)$, compared to the nEBF group (Table 1). Group differences and correlations between breastfeeding and demographic variables within the subset of participants with FSIQ scores showed similar results to the entire sample; however, gestational age at birth was no longer significantly different between groups.

\subsection{Breastfeeding exclusivity analysis}

Sex-by-group interactions were significant for whole brain FA $(p<0.001$; Table 2). Specifically, nEBF males had significantly higher FA than EBF males, whereas EBF females had higher FA than nEBF females (Fig. 2). A similar sex-by-group interaction was also significant for FA in most tracts (Table 2), with EBF females $>$ nEBF females and EBF males $<$ nEBF males (Fig. 2). Exceptions occurred in the fornix, the UF, and the SLF, where only females showed significant group differences for FA, and the ILF, where only males showed significant group differences for FA. The age-by-group interaction was significant in the body of the corpus callosum $(p=0.046)$, the pyramidal tract $(p<0.001)$, and the IFOF ( $p=0.009)$; the latter two tracts show steeper increases in FA with age in the EBF group (Fig. 3). All two-way interactions survived correction for multiple comparisons with the exception of the age-by-group interaction in the body of the corpus callosum. All findings remained significant after controlling for perinatal/sociodemographic covariates, child's FSIQ, and motion with the exception of the age-by-group interaction in the IFOF, which did not remain significant after controlling for child's FSIQ. Results for MD, AD, and RD are shown in the supplementary material (Results, Table S1, Table S2, Table S3, Figure S1 and Figure S2).

\subsection{Breastfeeding duration analysis}

The sex-by-duration interaction was significant for FA in the body of the corpus callosum ( $p=0.009)$, the cingulum $(p=0.015)$ and the ILF $(p=0.004$; Table 3$)$. As well, the duration-age interaction was significant for FA in the pyramidal tract ( $p=0.006$; Table 3 ) and there was a main effect of duration for FA in the SLF ( $p=0.017$; Table 3 ). The only finding that survived correction of multiple comparisons was the ILF, showing that lower FA was associated with longer breastfeeding for females, while no associations were noted between FA and duration with males (Fig. 4). This finding remained significant after controlling for perinatal/sociodemographic covariates, child's FSIQ, and motion. Additionally, as a small number of participants (6 participants; 16 datasets) were breastfed considerably longer than average, we re-ran the analysis without those participants; all results remained significant. MD, AD and $\mathrm{RD}$ results are shown in the supplementary material (Results, Table S4, Table S5, Table S6 and Figure S3). 
Table 1

Participant characteristics.

\begin{tabular}{|c|c|c|c|c|}
\hline a) Breastfeeding exclusivity analysis & Exclusively Breastfed & Not Exclusively Breastfed & $p$ & $\eta^{2}$ \\
\hline \multirow{2}{*}{\multicolumn{5}{|c|}{ Child }} \\
\hline & & & & \\
\hline Age at scan (years) & $3.90 \pm 0.92$ & $3.86 \pm 0.98$ & 0.614 & 0.042 \\
\hline Sex (males/females) & $18 \mathrm{M} / 32 \mathrm{~F}$ & $24 \mathrm{M} / 11 \mathrm{~F}$ & 0.003 & 0.371 \\
\hline Gestational age (weeks) & $39.7 \pm 1.0$ & $39.2 \pm 1.3$ & 0.028 & 0.431 \\
\hline Birthweight (grams) & $3419.4 \pm 391.9$ & $3377.1 \pm 464.9$ & 0.661 & 0.098 \\
\hline FSIQ ( $n=73 ; 296$ datasets) & $109.1 \pm 10.6$ & $110.0 \pm 13.9$ & 0.494 & 0.073 \\
\hline \multicolumn{5}{|l|}{ Mother } \\
\hline Post-secondary education (years) & $5.6 \pm 2.7$ & $6.1 \pm 2.7$ & 0.212 & 0.185 \\
\hline Age at delivery (years) & $31.3 \pm 2.7$ & $32.8 \pm 3.5$ & 0.059 & 0.480 \\
\hline Ethnicity (\% Caucasian) & 100 & 85.7 & 0.055 & 0.305 \\
\hline Family income (median) & $\$ 125,000-149,999$ & $\$ 150,000-\$ 174,999$ & 0.398 & 0.256 \\
\hline Total duration of any breastfeeding (years) & $1.37 \pm 0.68$ & $0.97 \pm 0.66$ & $<0.001$ & 0.597 \\
\hline \multicolumn{5}{|l|}{ Motion (all datasets) } \\
\hline Remaining diffusion-weighted volumes & $28 \pm 3$ & $28 \pm 3$ & 0.665 & 0.037 \\
\hline Remaining non-diffusion weighted volumes & $5 \pm 0$ & $5 \pm 1$ & 0.735 & 0.042 \\
\hline Restricted RMS displacement from previous volume & $0.36 \pm 0.24$ & $0.36 \pm 0.29$ & 0.956 & 0.006 \\
\hline b) Breastfeeding duration analysis & & $\mathbf{r}$ & $p$ & $\eta^{2}$ \\
\hline $\mathrm{N}=82(327$ datasets $)$ & - & - & - & \\
\hline \multicolumn{5}{|l|}{ Child } \\
\hline Age at scan (years) & $3.90 \pm 0.95$ & -0.018 & 0.714 & - \\
\hline Sex (males/females) & $41 \mathrm{M} / 41 \mathrm{~F}$ & - & 0.351 & 0.011 \\
\hline Gestational age (weeks) & $39.5 \pm 1.1$ & 0.206 & 0.080 & - \\
\hline Birthweight (grams) & $3407.6 \pm 416.2$ & 0.119 & 0.406 & - \\
\hline FSIQ ( $n=70 ; 292$ datasets) & $109.1 \pm 12.0$ & -0.159 & 0.125 & - \\
\hline \multicolumn{5}{|l|}{ Mother } \\
\hline Post-secondary education (years) & $5.8 \pm 2.7$ & 0.102 & 0.425 & - \\
\hline Age at delivery (years) & $31.8 \pm 3.1$ & -0.007 & 0.732 & - \\
\hline Ethnicity (\% Caucasian) & 93.9 & - & 0.322 & 0.012 \\
\hline Family income (median) & $\$ 125,000-149,999$ & - & 0.515 & 0.005 \\
\hline \multicolumn{5}{|l|}{ Motion (all datasets) } \\
\hline Remaining diffusion-weighted volumes & $28 \pm 3$ & -0.041 & 0.868 & - \\
\hline Remaining non-diffusion weighted volumes & $5 \pm 1$ & -0.009 & 0.458 & - \\
\hline Restricted RMS displacement from previous volume & $0.36 \pm 0.26$ & 0.041 & 0.465 & - \\
\hline
\end{tabular}

All data are presented as mean \pm SD unless otherwise indicated. Findings that meet the significance level set at $p<0.05$ are bolded.

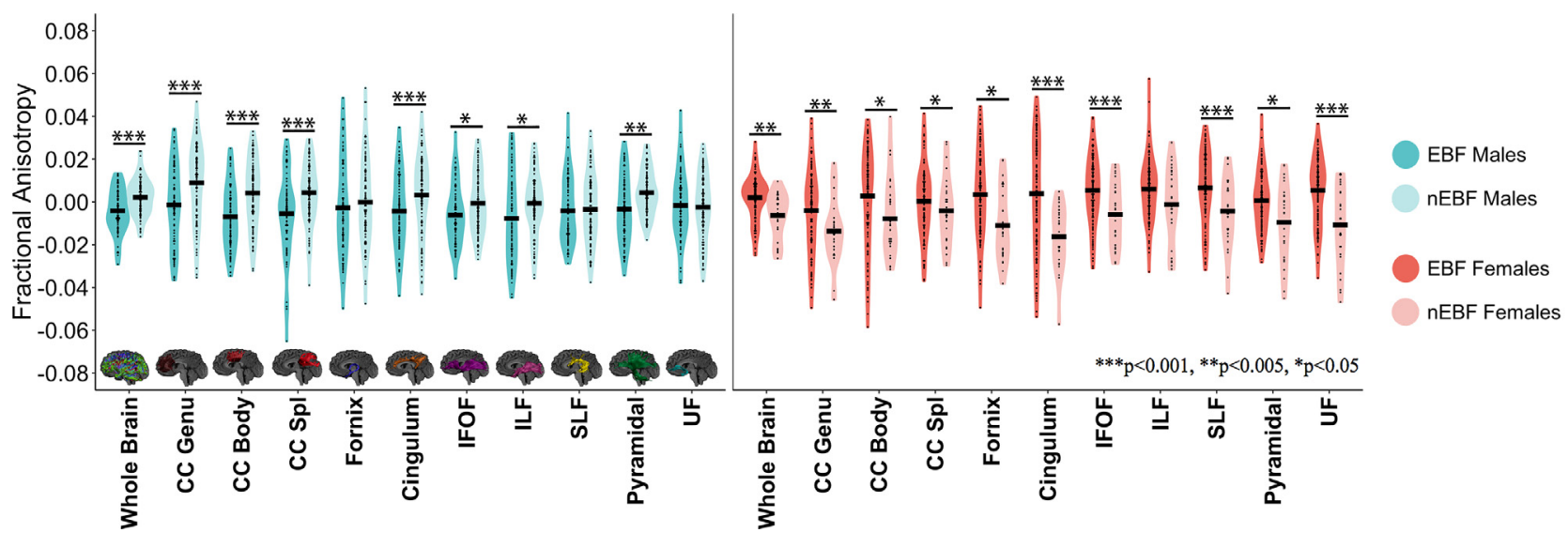

Fig. 2. Breastfeeding group by sex interactions for fractional anisotropy in the whole brain and individual white matter tracts. EBF males showed significantly lower FA than nEBF males in the whole brain and all individual tracts except the fornix, the SLF and the UF. EBF females showed significantly higher FA than nEBF females in the whole brain and all individual tracts except the ILF. Data is represented as mean $\pm 95 \%$ confidence interval for FA values for whole brain and individual tracts in EBF males vs. nEBF males and EBF females vs. nEBF females. FA values are corrected for age at the participant's scan. CC Genu $=$ genu of the corpus callosum, CC Body $=$ body of the corpus callosum, CC Splenium $=$ splenium of the corpus callosum. ${ }^{* * *} p<0.001 ;{ }^{* *} p<0.005 ;{ }^{*} p<0.05$.

\subsection{Within-subjects analysis}

There were significant group differences for FA slopes in the fornix ( $p=0.016)$, where the $\mathrm{nEBF}$ children show steeper age-related increases. As well, a significant group difference for FA slopes in the IFOF ( $p=0.009$ ), where the EBF children show steeper increases with age. No sex-by-group interactions were significant. There were no significant findings for total duration of breastfeeding.

\section{Discussion}

In this prospective longitudinal study, exclusive breastfeeding for the first 6 months of life and longer durations of breastfeeding were associated with altered white matter structure in early childhood. Most findings remained significant after accounting for potential confounders and revealed that exclusive breastfeeding is associated with sex-specific white matter differences in young children. 
Table 2

Linear mixed effects results analyzing differences in FA between breastfeeding groups. Percent differences are given relative to the not exclusively breastfed group.

\begin{tabular}{|c|c|c|c|c|c|}
\hline \multirow[b]{3}{*}{ Whole Brain } & \multicolumn{5}{|c|}{ Fractional Anisotropy } \\
\hline & \multicolumn{3}{|c|}{ Main Effects } & \multicolumn{2}{|c|}{ Interactions } \\
\hline & Age & Sex & Group & Sex-by-Group & Age-by-Group \\
\hline $\operatorname{PE}\left(95 \% \mathrm{CI} 10^{-3}\right)$ & $6.0 \mathrm{E}-03(5.3,6.7)$ & 8.6E-03 $(4.6,12.6)$ & $9.1 \mathrm{E}-03(5.3,12.8)$ & $-1.5 \mathrm{E}-02(-20.0,-11.0)$ & - \\
\hline$t$-value ( $p$-value) & $16.117(<0.001)$ & $4.188(0.459)$ & $4.760(0.247)$ & $-6.803(<\mathbf{0 . 0 0 1})$ & - \\
\hline \% Difference & & & & $\mathrm{M}:-1.5 \% \mathrm{~F}: 1.8 \%$ & \\
\hline \multicolumn{6}{|l|}{ Genu of the CC } \\
\hline $\mathrm{PE}\left(95 \% \mathrm{CI} 10^{-3}\right)$ & $8.4 \mathrm{E}-03(6.7,10.0)$ & $2.3 \mathrm{E}-02(15.4,30.5)$ & $1.2 \mathrm{E}-02(4.6,18.9)$ & $-2.2 \mathrm{E}-02(-30.8,-13.2)$ & - \\
\hline$t$-value ( $p$-value) & $10.834(<0.001)$ & $6.004(<0.001)$ & $3.244(0.734)$ & $-4.986(<\mathbf{0 . 0 0 1})$ & - \\
\hline \% Difference & & & & $\mathrm{M}:-2.2 \% \mathrm{~F}: 1.9 \%$ & \\
\hline \multicolumn{6}{|l|}{ Body of the CC } \\
\hline $\mathrm{PE}\left(95 \% \mathrm{CI} 10^{-3}\right)$ & $4.6 \mathrm{E}-03(2.1,7.1)$ & $-3.7 \mathrm{E}-03(-21.2,13.7)$ & $9.8 \mathrm{E}-03(2.3,17.4)$ & $-2.1 \mathrm{E}-02(-30.2,-11.9)$ & $3.4 \mathrm{E}-03(0.06,6.7)$ \\
\hline$t$-value ( $p$-value) & $3.561(<0.001)$ & $-0.422(0.085)$ & $2.574(0.767)$ & $-4.542(<\mathbf{0 . 0 0 1})$ & $2.008(0.046)$ \\
\hline \% Difference & & & & M: $-2.3 \%$ F: $2.1 \%$ & $3 y:-0.5 \%, 7 y:-1.6 \%$ \\
\hline \multicolumn{6}{|l|}{ Splenium of the CC } \\
\hline $\mathrm{PE}\left(95 \% \mathrm{Cl} 10^{-3}\right)$ & $5.4 \mathrm{E}-03(-72.2,72.2)$ & $8.6 \mathrm{E}-03(1.8,15.3)$ & $6.7 \mathrm{E}-03(0.7,12.7)$ & $-1.2 \mathrm{E}-02(19.6,-5.3)$ & - \\
\hline$t$-value ( $p$-value) & $17.045(0.688)$ & $2.502(0.188)$ & $2.199(0.785)$ & $-3.564(\mathbf{0 . 0 0 1})$ & - \\
\hline \% Difference & & & & M: $-1.8 \%$ F: $0.8 \%$ & \\
\hline \multicolumn{6}{|l|}{ Fornix } \\
\hline PE $\left(95 \%\right.$ CI $\left.10^{-3}\right)$ & 7.6E-03 (5.8, 9.4) & $1.0 \mathrm{E}-02(21.9,18.5)$ & $1.4 \mathrm{E}-02(5.8,21.8)$ & $-1.6 \mathrm{E}-02(-26.0,-6.4)$ & - \\
\hline$t$-value ( $p$-value) & $8.497(<0.001)$ & $2.498(0.372)$ & $3.404(0.022)$ & $-3.261(\mathbf{0 . 0 0 1})$ & - \\
\hline \% Difference & & & & $\mathrm{M}:-0.8 \% \mathrm{~F}: 3.8 \%$ & \\
\hline \multicolumn{6}{|l|}{ Cingulum } \\
\hline $\mathrm{PE}\left(95 \% \mathrm{CI} 10^{-3}\right)$ & $8.3 \mathrm{E}-03(6.5,10.1)$ & $1.9 \mathrm{E}-02(10.9,27.8)$ & $1.9 \mathrm{E}-02(11.1,27.8)$ & $-2.7 \mathrm{E}-02(-37.1,-16.8)$ & - \\
\hline$t$-value ( $p$-value) & $9.036(<0.001)$ & $4.502(0.025)$ & $4.596(0.021)$ & $-5.213(<\mathbf{0 . 0 0 1})$ & - \\
\hline \% Difference & & & & $\mathrm{M}:-1.8 \% \mathrm{~F}: 4.9 \%$ & \\
\hline \multicolumn{6}{|l|}{ IFOF } \\
\hline $\mathrm{PE}\left(95 \% \mathrm{CI} 10^{-3}\right)$ & $6.5 \mathrm{E}-03(4.6,8.5)$ & $5.8 \mathrm{E}-03(-0.2,11.7)$ & $-2.0 \mathrm{E}-03(-14.4,10.5)$ & $-2.0 \mathrm{E}-02(-26.7,-13.0)$ & $3.2 \mathrm{E}-03(0.8,5.6)$ \\
\hline$t$-value ( $p$-value) & $6.587(<0.001)$ & $1.909(0.017)$ & $-0.313(0.047)$ & $-5.727(<\mathbf{0 . 0 0 1})$ & $2.645(\mathbf{0 . 0 0 9})$ \\
\hline \% Difference & & & & $\mathrm{M}:-1.3 \% \mathrm{~F}: 2.5 \%$ & $3 y:-0.7 \%, 7 y: 2.8 \%$ \\
\hline \multicolumn{6}{|l|}{ ILF } \\
\hline PE $\left(95 \% \mathrm{CI} 10^{-3}\right)$ & $1.1 \mathrm{E}-02(9.7,12.5)$ & $4.7 \mathrm{E}-04(-6.2,7.2)$ & $6.0 \mathrm{E}-03(-0.2,12.1)$ & $-1.3 \mathrm{E}-02(-20.8,-5.3)$ & - \\
\hline$t$-value ( $p$-value) & $15.739(<0.001)$ & $0.137(0.002)$ & $1.909(0.788)$ & $-3.324(\mathbf{0 . 0 0 1})$ & - \\
\hline \% Difference & & & & $\mathrm{M}:-1.8 \% \mathrm{~F}: 1.5 \%$ & \\
\hline \multicolumn{6}{|l|}{ SLF } \\
\hline $\mathrm{PE}\left(95 \% \mathrm{CI} 10^{-3}\right)$ & $6.2 \mathrm{E}-03(4.9,7.5)$ & $1.1 \mathrm{E}-03(-5.5,7.7)$ & $1.2 \mathrm{E}-02(5.4,18.4)$ & $-1.4 \mathrm{E}-02(-21.5,-5.9)$ & - \\
\hline$t$-value ( $p$-value) & $9.267(<0.001)$ & $0.322(0.004)$ & $3.596(0.012)$ & $-3.454(<\mathbf{0 . 0 0 1})$ & - \\
\hline \% Difference & & & & M: $-0.2 \%$ F: 2.5 & \\
\hline \multicolumn{6}{|l|}{ Pyramidal } \\
\hline PE $\left(95 \%\right.$ CI $\left.10^{-3}\right)$ & $4.8 \mathrm{E}-03(2.9,6.8)$ & $1.4 \mathrm{E}-02(8.7,19.8)$ & $-1.3 \mathrm{E}-02(-24.8,-0.6)$ & $-2.0 \mathrm{E}-02(-26.2,-13.6)$ & $5.1 \mathrm{E}-03(2.7,7.4)$ \\
\hline$t$-value ( $p$-value) & $4.912(<0.001)$ & $5.071(0.008)$ & $-2.071(<0.001)$ & $-6.223(<\mathbf{0 . 0 0 1})$ & $4.299(<\mathbf{0 . 0 0 1})$ \\
\hline \% Difference & & & & $\mathrm{M}:-1.6 \% \mathrm{~F}: 2.0 \%$ & $3 y: 0.003 \%, 7 y: 0.2 \%$ \\
\hline \multicolumn{6}{|l|}{ UF } \\
\hline PE $\left(95 \%\right.$ CI $\left.10^{-3}\right)$ & $6.1 \mathrm{E}-03(4.8,7.4)$ & $8.3 \mathrm{E}-03(1.8,14.8)$ & $1.8 \mathrm{E}-02(11.5,24.0)$ & $-1.6 \mathrm{E}-02(-24.0,-9.0)$ & - \\
\hline$t$-value ( $p$-value) & $9.196(<0.001)$ & $2.522(0.977)$ & $5.585(<0.001)$ & $-4.326(<\mathbf{0 . 0 0 1})$ & - \\
\hline \% Difference & & & & M: $0.2 \% \mathrm{~F}: 4.1 \%$ & \\
\hline
\end{tabular}

If interactions were not significant, they were removed from the model. Significant findings that survived correction for multiple comparisons are bolded. Percent difference was calculated as (FAnEBF FAEBF) $/ \mathrm{FAnEBF} . \mathrm{PE}=$ parameter estimate, $\mathrm{CI}=$ confidence interval, $\mathrm{CC}=$ corpus callosum, $\mathrm{M}=\mathrm{male}$, $\mathrm{F}=$ female, $3 \mathrm{y}=3$ years of age, $7 \mathrm{y}=7$ years of age.
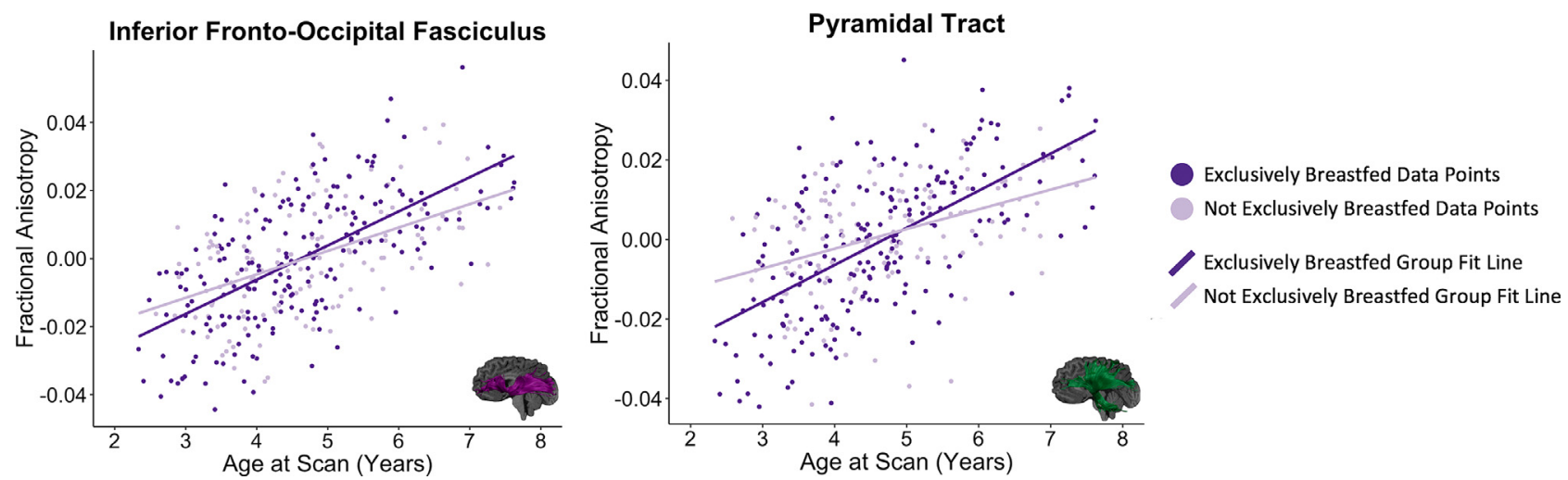

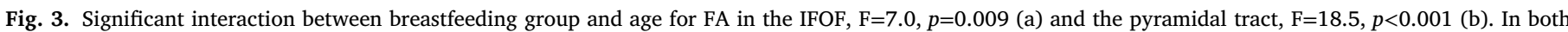
tracts, the exclusively breastfed group shows steeper increases in FA with age. All FA values are corrected for sex. 
Table 3

Linear mixed effects results analyzing associations between FA and total duration of any breastfeeding.

\begin{tabular}{|c|c|c|c|c|c|}
\hline & \multicolumn{5}{|c|}{ Fractional Anisotropy } \\
\hline & \multirow{2}{*}{\multicolumn{2}{|c|}{$\begin{array}{l}\text { Main Effects } \\
\text { Sex }\end{array}$}} & \multirow[b]{2}{*}{ Duration } & \multicolumn{2}{|c|}{ Interaction } \\
\hline & & & & Sex-by-Duration & Age-by-Duration \\
\hline \multicolumn{6}{|l|}{ Whole Brain } \\
\hline $\mathrm{PE}\left(95 \% \mathrm{CI} 10^{-3}\right)$ & $6.3 \mathrm{E}-03(5.7,7.0)$ & $-2.5 \mathrm{E}-03(-3.9,-1.1)$ & $-1.3 \mathrm{E}-03(-2.8,0.3)$ & - & - \\
\hline$t$-value ( $p$-value) & $18.704(<0.001)$ & $-3.536(<0.001)$ & $-1.576(0.116)$ & - & - \\
\hline \multicolumn{6}{|l|}{ Genu of the CC } \\
\hline $\mathrm{PE}\left(95 \% \mathrm{CI} 10^{-3}\right)$ & $9.0 \mathrm{E}-03(7.7,10.4)$ & $7.7 \mathrm{E}-03(4.7,10.6)$ & $1.9 \mathrm{E}-04(-2.8,3.2)$ & - & - \\
\hline$t$-value ( $p$-value) & $0.126(<0.001)$ & $5.173(<0.001)$ & $12.822(0.900)$ & - & - \\
\hline \multicolumn{6}{|l|}{ Body of the CC } \\
\hline $\mathrm{PE}\left(95 \% \mathrm{CI} 10^{-3}\right)$ & $6.5 \mathrm{E}-03(4.8,8.2)$ & $1.0 \mathrm{E}-02(1.4,19.5)$ & $4.5 \mathrm{E}-03(-0.7,9.8)$ & $-8.8 \mathrm{E}-03(-15.4,-2.2)$ & - \\
\hline$t$-value ( $p$-value) & $7.415(<0.001)$ & $2.268(0.024)$ & $1.693(0.930)$ & $-2.630(0.009)$ & - \\
\hline \multicolumn{6}{|c|}{ Splenium of the CC } \\
\hline $\mathrm{PE}\left(95 \% \mathrm{CI} 10^{-3}\right)$ & $5.5 \mathrm{E}-03(4.8,6.2)$ & $-2.0 \mathrm{E}-03(-3.2,-0.7)$ & $-1.3 \mathrm{E}-03(-3.5,1.0)$ & - & - \\
\hline$t$-value ( $p$-value) & $-1.130(<0.001)$ & $-3.248(0.001)$ & $16.421(0.259)$ & - & - \\
\hline \multicolumn{6}{|l|}{ Fornix } \\
\hline $\mathrm{PE}\left(95 \% \mathrm{CI} 10^{-3}\right)$ & $7.4 \mathrm{E}-03(5.5,9.2)$ & $-9.7 \mathrm{E}-04(-5.3,3.3)$ & $1.4 \mathrm{E}-04(-3.2,3.5)$ & - & - \\
\hline$t$-value ( $p$-value) & $7.900(<0.001)$ & $-0.441(0.659)$ & $0.080(0.936)$ & - & - \\
\hline \multicolumn{6}{|l|}{ Cingulum } \\
\hline $\mathrm{PE}\left(95 \% \mathrm{CI} 10^{-3}\right)$ & $8.2 \mathrm{E}-03(6.3,10.1)$ & $1.3 \mathrm{E}-02(2.6,22.8)$ & $9.1 \mathrm{E}-03(3.3,14.9)$ & $-9.1 \mathrm{E}-03(-16.4,-1.8)$ & - \\
\hline$t$-value ( $p$-value) & $8.449(<0.001)$ & $2.482(0.014)$ & $3.088(0.014)$ & $-2.455(0.015)$ & - \\
\hline \multicolumn{6}{|l|}{ IFOF } \\
\hline $\mathrm{PE}\left(95 \% \mathrm{CI} 10^{-3}\right)$ & $8.6 \mathrm{E}-03(-1.8,3.1)$ & $-7.0 \mathrm{E}-03(-10.1,-3.9)$ & $6.8 \mathrm{E}-04(7.3,9.8)$ & - & - \\
\hline$t$-value ( $p$-value) & $13.618(<0.001)$ & $-4.410(<0.001)$ & $0.542(0.588)$ & - & - \\
\hline \multicolumn{6}{|l|}{ ILF } \\
\hline $\mathrm{PE}\left(95 \% \mathrm{CI} 10^{-3}\right)$ & $1.1 \mathrm{E}-02(9.9,12.8)$ & $-1.8 \mathrm{E}-02(-25.7,-10.3)$ & $-6.7 \mathrm{E}-03(-11.3,-2.2)$ & $8.4 \mathrm{E}-03(2.7,14.1)$ & - \\
\hline$t$-value ( $p$-value) & $15.451(<0.001)$ & $-4.583(<0.001)$ & $-2.930(0.082)$ & $2.907(\mathbf{0 . 0 0 4})$ & - \\
\hline \multicolumn{6}{|l|}{ SLF } \\
\hline $\mathrm{PE}\left(95 \% \mathrm{CI} 10^{-3}\right)$ & $6.2 \mathrm{E}-03(4.9,7.5)$ & $-9.2 \mathrm{E}-03(-12.6,-5.9)$ & $-3.2 \mathrm{E}-03(-5.8,-0.6)$ & - & - \\
\hline$t$-value ( $p$-value) & $9.148(<0.001)$ & $-5.491(<0.001)$ & $-2.398(0.017)$ & - & - \\
\hline \multicolumn{6}{|l|}{ Pyramidal } \\
\hline $\mathrm{PE}\left(95 \% \mathrm{CI} 10^{-3}\right)$ & $4.9 \mathrm{E}-03(2.2,7.6)$ & $1.3 \mathrm{E}-04(-2.1,2.4)$ & $-1.8 \mathrm{E}-02(-27.2,-7.9)$ & - & $2.9 \mathrm{E}-03(0.8,4.9)$ \\
\hline$t$-value ( $p$-value) & $3.534(<0.001)$ & $0.114(0.909)$ & $-3.595(<0.001)$ & - & $2.782(0.006)$ \\
\hline \multicolumn{6}{|l|}{ UF } \\
\hline $\mathrm{PE}\left(95 \% \mathrm{CI} 10^{-3}\right)$ & $6.4 \mathrm{E}-03(5.0,7.8)$ & $-4.4 \mathrm{E}-03(-7.8,-1.0)$ & $2.4 \mathrm{E}-03(-0.3,5.0)$ & - & - \\
\hline$t$-value ( $p$-value) & $8.961(<0.001)$ & $-2.569(0.011)$ & $1.748(0.082)$ & - & - \\
\hline
\end{tabular}

If interactions were not significant, they were removed from the model. Significant findings that survived correction for multiple comparisons are bolded. $\mathrm{PE}=$ parameter estimate, $\mathrm{CI}=$ confidence interval, $\mathrm{CC}=$ corpus callosum.

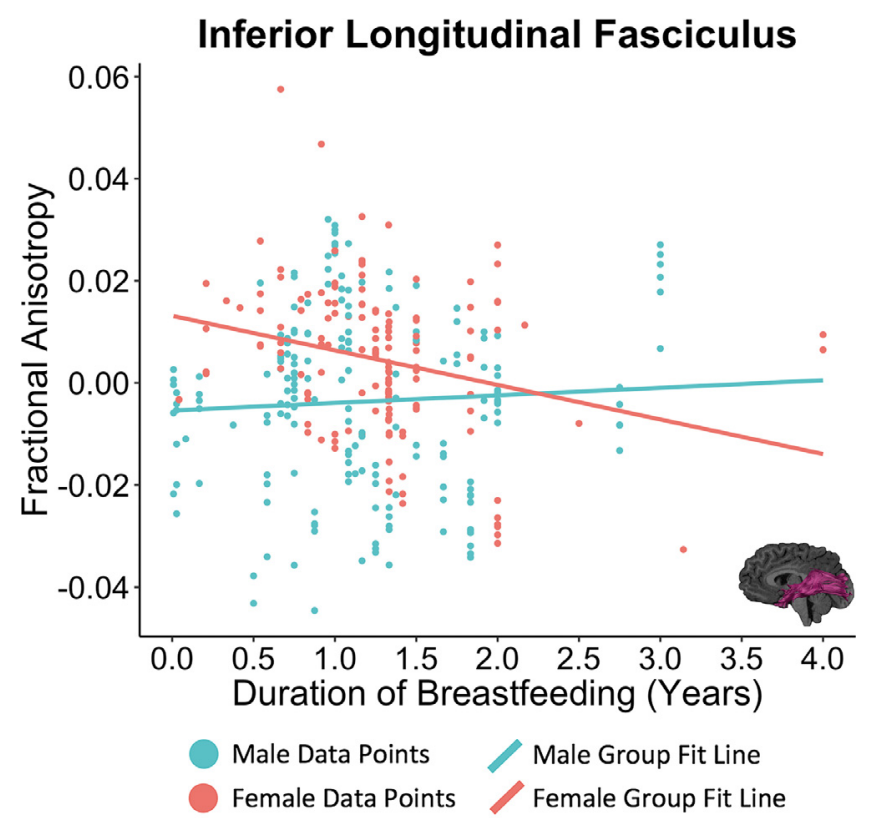

Fig. 4. Significant interactions between breastfeeding duration and child's sex for FA in the inferior longitudinal fasciculus $(F=8.5, p=0.004)$, where FA decreases as duration of breastfeeding increases for females. All FA values are corrected for age at the participant's scan.
Females who were EBF for the first 6 months had significantly higher FA on both a global and regional level compared to nEBF females. The opposite was observed in males: nEBF boys had significantly higher FA at a global and regional level. Our findings in females align with previous research in full-term and preterm infants and young children where breastfeeding exclusivity and/or duration was associated with higher myelin water fraction (Deoni et al., 2018; Deoni et al., 2013) or higher FA (Bauer et al., 2020; Blesa et al., 2019). Interestingly, in studies that examined sex differences, no associations were reported between breastfeeding and white matter microstructure in term-born school-aged females (Ou et al., 2014) or white matter volume in preterm adolescent females (Isaacs et al., 2010). In our study, the largest percent differences in FA between EBF and nEBF females were noted in the cingulum (4.9\%) and the uncinate fasciculus (4.1\%). For males, our results are in contrast to previous research that reported associations between breastfeeding exclusivity and/or duration, and higher myelin water fraction (Deoni et al., 2018; Deoni et al., 2013), higher FA (Bauer et al., 2020; Blesa et al., 2019; Ou et al., 2014) or higher white matter volume (Isaacs et al., 2010). The largest percent differences in FA between EBF and $n E B F$ males were noted in the genu $(-2.2 \%)$ and the body of the corpus callosum $(-2.3 \%)$, which are smaller than differences reported in previous research, perhaps due to the age range examined (Ou et al., 2014).

Sex differences in white matter development may help explain the differing associations in females versus males. Throughout infancy, childhood and into early adulthood, FA increases throughout the brain (Dubois et al., 2014; Hermoye et al., 2006; Krogsrud et al., 2016; Lebel et al., 2008; Reynolds et al., 2019). In young children, these developmental processes vary slightly between sexes, with young boys 
showing faster rates of change (steeper slopes) than girls. On the contrary, young girls have higher initial maturity (i.e., higher FA), suggesting that they undergo earlier brain development compared to boys (Reynolds et al., 2019). Similar observations have been made in older children and adolescents (Clayden et al., 2012; Seunarine et al., 2015; Wang et al., 2012). It is possible that females are further along in terms of white matter maturation compared to males, which may lead to sexually dimorphic breastfeeding-brain structure associations. As white matter continues to develop through late childhood and adolescence, it is possible that the association between breastfeeding and anisotropy will shift, such that older EBF males may have higher FA than older nEBF males. This would align with previous research findings in older, schoolaged children (4- to 8.5-years-old), which noted that breastfed males had higher FA than formula-fed males in whole brain and regional white matter (Bauer et al., 2020; Ou et al., 2014). This is, in part, supported by the fact that the EBF group in our sample showed steeper age-related increases in FA in some white matter tracts when compared to the nEBF group. Continued follow-up in this sample and more longitudinal studies will help to further understand associations between developmental trajectories of white matter and breastfeeding, clarifying whether the observed associations in young children persist across ages or whether they are unique to early childhood.

The most prominent differences between breastfeeding groups were in the cingulum, a tract associated with social-emotional processing and memory (Bubb et al., 2018) followed by the corpus callosum (Aboitiz and Montiel, 2003), which is involved in integrating and transferring information between hemispheres. Other tracts with notable differences included the IFOF, which underlies visual processing and early language skills (Almairac et al., 2015), the pyramidal tract which underlies motor performance (Jang, 2014; Yeo et al., 2014), as well as fronto-temporal tracts, the SLF and the UF, which are associated with higher-order cognitive functions, executive function, language, and social-emotional processing (Olson et al., 2015; Urger et al., 2015). Across numerous studies, breastfeeding has been associated with functions such as social-emotional processing (Oddy et al., 2010), motor performance (Belfort et al., 2016; Michels et al., 2017), cognition and memory (Belfort et al., 2016), as well as language (Dee et al., 2006). Recent work showed that exclusively breastfed girls, compared to girls not exclusively breastfed, scored higher on cognitive assessments during infancy and the preschool years (6-60 months), while no differences were observed in boys at this age (Guzzardi et al., 2020). These associations between breastfeeding and neurodevelopmental outcomes may, in part, be associated with alterations to underlying white matter tracts that correspond to these functions.

One hypothesized mechanism by which breastfeeding may be associated with white matter development is the nutritional content of breastmilk. Breastmilk contains a variety of proteins, lipids, and other macroand micro-nutrients that are necessary for white matter development (Martin et al., 2016). For example, choline is abundant in breastmilk and is a precursor to phosphatidylcholine and sphingomyelin, which are required for the synthesis of the myelin sheath (Oshida et al., 2003; Saher et al., 2005). Similarly, long-chain polyunsaturated fatty acids in breastmilk, specifically docosahexaenoic acid and arachidonic acid, support neuronal growth and myelination (Chang et al., 2009; Guesnet and Alessandri, 2011; Hadley et al., 2016; Hoffman et al., 2009). Another possible mechanism is the increased opportunity for didactic and affectionate mother-child interactions during breastfeeding, which may contribute to the development of white matter tracts (Krol and Grossmann, 2018). It is possible that males and females respond differently to their early nutritional environments, which may subsequently alter neurodevelopment (Galante et al., 2018; Tottman et al., 2020).

While these sex-specific findings were robust, there are limitations that are important to consider. Participants were primarily of moderateto-high socioeconomic status and most identified as Caucasian; therefore, these results may not be representative of demographically different populations. While this sample limits the generalizability of our findings, it does ensure limited differences in perinatal and sociodemographic characteristics between the EBF and nEBF groups, allowing for better control of potential confounding factors. Furthermore, the feeding questions did not gather specific quantities of milk the child ingested from breastfeeding or formula-feeding, nor did they ask about method of feeding breastmilk (i.e., at the breast or via bottle), which could affect the associations observed here. This study also had few participants that were exclusively formula-fed, which may have reduced the power to detect group differences. Lastly, it is important to note that the duration of breastfeeding in our sample ( $14.3 \pm 8.4$ months) is slightly, but not dramatically, higher than durations reported in other neuroimaging studies with samples in the United States ranging from 9.9 7.1 months (Bauer et al., 2020) to $12.5 \pm 6.2$ months (Ou et al., 2014) on average. These durations are all lower than the 2-year duration recommended by the WHO (WHO, 2003).

\section{Conclusions}

In this predominantly white sample of higher socioeconomic status, breastfeeding exclusivity during the first 6 months and total duration of breastfeeding are associated with sex-specific global and regional alterations to white matter development in young children. These complex associations should compel future research to comprehensively consider sex differences, age-related changes, and other covariates in their analysis. Understanding associations between brain development and breastfeeding is essential for health education and promotion strategies as these results suggest that breastfeeding is associated with long-term neurodevelopmental changes that persist into early childhood.

\section{Funding Source}

This was supported by grants from the Canadian Institutes of Health Research (CIHR) (IHD-134090; MOP-123535; MOP-136797, New Investigator Award to C.L), and the Alberta Children's Hospital Foundation. Funding to establish the APrON cohort was provided by a grant from Alberta Innovates-Health Solutions (AIHS). P.K. was supported by an Alberta Children's Hospital Research Institute Graduate Scholarship, a Queen Elizabeth II Graduate Scholarship and a Harley N. Hotchkiss Graduate Scholarship. J.E.R. was supported by an Eyes High University of Calgary Postdoctoral Scholarship, a T. Chen Fong Postdoctoral Fellowship in Medical Imaging Science, and a CIHR postdoctoral fellowship (MFE-164703). M.E.G. was supported by a Queen Elizabeth II Graduate Scholarship.

\section{Author Contributions}

Preeti Kar: conceptualization, methodology, formal analysis, investigation, writing the original draft and visualization, reviewing and editing the draft. Jess E. Reynolds: formal analysis, investigation, reviewing and editing the draft. Melody N. Grohs: formal analysis, investigation, reviewing and editing the draft. Megan Jarman: formal analysis, investigation, reviewing and editing the draft. Rhonda C. Bell: conceptualization, methodology, formal analysis, investigation, reviewing and editing the draft. funding acquisition, resources, supervision for MJ. Deborah Dewey: conceptualization, methodology, formal analysis, investigation, reviewing and editing the draft, funding acquisition, supervision for MEG. Catherine Lebel: conceptualization, methodology, writing the original draft, visualization, formal analysis, investigation, reviewing and editing the draft, project administration, funding acquisition, resources supervision for PK, JER, and MNG.

Data and code availability. Neuroimaging data is publicly available on the Open Science Framework here: https://osf.io/axz5r/ (Reynolds, Long et al. 2020). Alberta Pregnant Outcomes and Nutrition (APrON) cohort breastfeeding data is available on SAGE https://dataverse.library.ualberta.ca/dataverse/SAGE. 


\section{Declaration of Competing interests}

The authors declare that they have no known competing financial interests or personal relationships that could have appeared to influence the work reported in this paper.

\section{Acknowledgements}

The authors acknowledge the contributions of the APrON Study Team. We are extremely grateful to all the families who took part in this study and the whole APrON team (http://www.apronstudy.ca), investigators, research assistants, graduate and undergraduate students, volunteers, clerical staff and mangers. This cohort was established by an interdisciplinary team grant from Alberta Innovates Health Solutions (formally the Alberta Heritage Foundation for Medical Research) and additional funding (see above) assisted with the collection and analysis of data presented in this manuscript.

\section{Supplementary materials}

Supplementary material associated with this article can be found, in the online version, at doi:10.1016/j.neuroimage.2020.117520.

\section{References}

Aboitiz, F., Montiel, J., 2003. One hundred million years of interhemispheric communication: the history of the corpus callosum. Braz. J. Med. Biol. Res. 36, 409-420.

Almairac, F., Herbet, G., Moritz-Gasser, S., de Champfleur, N.M., Duffau, H., 2015. The left inferior fronto-occipital fasciculus subserves language semantics: a multilevel lesion study. Brain Struct. Funct. 220, 1983-1995.

Anderson, J.W., Johnstone, B.M., Remley, D.T., 1999. Breast-feeding and cognitive development: a meta-analysis. Am. J. Clin. Nutr. 70, 525-535.

Andersson, J.L.R., Sotiropoulos, S.N., 2016. An integrated approach to correction for off-resonance effects and subject movement in diffusion MR imaging. NeuroImage. 1063-1078.

Batalle, D., Hughes, E.J., Zhang, H., Tournier, J.D., Tusor, N., Aljabar, P., Wali, L., Alexander, D.C., Hajnal, J.V., Nosarti, C., Edwards, A.D., Counsell, S.J., 2017. Early development of structural networks and the impact of prematurity on brain connectivity. NeuroImage 149, 379-392.

Bauer, C.E., Lewis, J.W., Brefczynski-Lewis, J., Frum, C., Schade, M.M., Haut, M.W., Montgomery-Downs, H.E., 2020. Breastfeeding duration is associated with regional, but not global, differences in white matter tracts. Brain Sci. 10, 1-12.

Belfort, M.B., Anderson, P.J., Nowak, V.A., Lee, K.J., Molesworth, C., Thompson, D.K., Doyle, L.W., Inder, T.E., 2016. Breast milk feeding, brain development, and neurocognitive outcomes: a 7-year longitudinal study in infants born at less than 30 weeks' gestation. J. Pediatr. 177, 133-139 e131.

Bernard, J.Y., Agostini, M.D., Forhan, A., Alfaiate, T., Bonet, M., Kaminski, M., Lauzonguillain, B.D., Charles, M.-a., Heude, B., Study, M.-c.C., 2013. Breastfeeding duration and cognitive development at 2 and 3 years of age in the EDEN mother - child cohort.

Blesa, M., Sullivan, G., Anblagan, D., Telford, E., Quigley, A.J., Sparrow, S.A., Serag, A., Scott, I., Bastin, M.E., Boardman, J.P., 2019. Early breast milk exposure modifies brain connectivity in preterm infants. NeuroImage 184, 431-439.

Brito, N.H., Noble, K.G., 2014. Socioeconomic status and structural brain development. Front. Neurosci. 8, 1-12.

Bubb, E.J., Metzler-Baddeley, C., Aggleton, J.P., 2018. The cingulum bundle: anatomy, function, and dysfunction. Neurosci. Biobehav. Rev. 92, 104-127.

Chang, C.-Y., Ke, D.-S., Chen, J.-Y., 2009. Essential fatty acids and human brain. Acta Neurol. Taiwan. 18, 231-241.

Clayden, J.D., Jentschke, S., Muñoz, M., Cooper, J.M., Chadwick, M.J., Banks, T., Clark, C.A., Vargha-Khadem, F., 2012. Normative development of white matter tracts: Similarities and differences in relation to age, gender, and intelligence. Cerebr. Cortex $22,1738-1747$

Dee, D.L., Li, R., Lee, L.-C., Grummer-Strawn, L.M., 2006. Associations between breastfeeding practices and young children 's language and motor.

Deoni, S., Dean, D., Joelson, S., O'Regan, J., Schneider, N., 2018. Early nutrition influences developmental myelination and cognition in infants and young children. NeuroImage 178, 649-659.

Deoni, S., Dean, D.C., Piryatinsky, I., O'Muircheartaigh, J., Waskiewicz, N., Lehman, K., Han, M., Dirks, H., 2013. Breastfeeding and early white matter development: a crosssectional study. NeuroImage 82, 77-86.

Deoni, S.C.L., Dean, D.C., O'Muircheartaigh, J., Dirks, H., Jerskey, B.A., 2012. Investigating white matter development in infancy and early childhood using myelin water faction and relaxation time mapping. NeuroImage 63, 1038-1053.

Der, G., Batty, G.D., Deary, I.J., 2006. Effect of breast feeding on intelligence in children: prospective study, sibling pairs analysis, and meta-analysis. BMJ 333, 945 (Clinical research ed.)

Dubois, J., Dehaene-Lambertz, G., Kulikova, S., Poupon, C., Hüppi, P.S., Hertz-Pannier, L., 2014. The early development of brain white matter: a review of imaging studies in fetuses, newborns and infants. Neuroscience 276, 48-71.
Galante, L., Milan, A.M., Reynolds, C.M., Cameron-Smith, D., Vickers, M.H., Pundir, S., 2018. Sex-specific human milk composition: the role of infant sex in determining early life nutrition. Nutrients 10, 1-11.

Gibbs, B.G., Forste, R., 2014. Breastfeeding, parenting, and early cognitive development. J. Pediatr. 164, 487-493.

Gibson-Davis, C.M., Brooks-Gunn, J., 2006. Breastfeeding and verbal ability of 3-year-olds in a multicity sample. Pediatrics 118, e1444-e1451.

Guesnet, P., Alessandri, J.M., 2011. Docosahexaenoic acid (DHA) and the developing central nervous system (CNS) - implications for dietary recommendations. Biochimie 93 , 7-12.

Guzzardi, M.A., Granziera, F., Sanguinetti, E., Ditaranto, F., Muratori, F., Iozzo, P., 2020. Exclusive breastfeeding predicts higher hearing-language development in girls of preschool age. Nutrients 1-12.

Hadley, K.B., Ryan, A.S., Forsyth, S., Gautier, S., Salem, N., 2016. The essentiality of arachidonic acid in infant development. Nutrients 8.

Hermoye, L., Saint-Martin, C., Cosnard, G., Lee, S.K., Kim, J., Nassogne, M.C., Menten, R., Clapuyt, P., Donohue, P.K., Hua, K., Wakana, S., Jiang, H., Van Zijl, P.C.M., Mori, S., 2006. Pediatric diffusion tensor imaging: normal database and observation of the white matter maturation in early childhood. NeuroImage 29, 493-504.

Hoffman, D.R., Boettcher, J.A., Diersen-Schade, D.A., 2009. Toward optimizing vision and cognition in term infants by dietary docosahexaenoic and arachidonic acid supplementation: a review of randomized controlled trials. Prostaglandins Leukotrienes Essential Fatty Acids 81, 151-158.

Horwood, L.J., Darlow, B.A., Mogridge, N., 2001. Breast milk feeding and cognitive ability at 7-8 years. Archives of disease in childhood. Fetal Neonatal Edit. 84, F23-F27.

Isaacs, E.B., Fischl, B.R., Quinn, B.T., Chong, W.K., Gadian, D.G., Lucas, A., 2010. Impact of breast milk on IQ, brain size and white matter development. Pediatr. Res. 67, 357-362.

Jacobson, S.W., Chiodo, L.M., Jacobson, J.L., 1999. Breastfeeding effects on intelligence quotient in 4- and 11-year-old children. Pediatrics 103 e71-e71.

Jain, A., Concato, J., Leventhal, J.M., 2002. How good is the evidence linking breastfeeding and intelligence? Pediatrics 109, 1044-1053.

Jang, S.H., 2014. The corticospinal tract from the viewpoint of brain rehabilitation. J. Rehabil. Med. 46, 193-199.

Jessri, M., Farmer, A.P., Maximova, K., Willows, N.D., Bell, R.C., 2013. Predictors of exclusive breastfeeding: observations from the Alberta pregnancy outcomes and nutrition (APrON) study.

Kaplan, B.J., Giesbrecht, G.F., Leung, B.M.Y., Field, C.J., Dewey, D., Bell, R.C., Manca, D.P., O’Beirne, M., Johnston, D.W., Pop, V.J., Singhal, N., Gagnon, L., Bernier, F.P., Eliasziw, M., Mccargar, L.J., Kooistra, L., Farmer, A., Cantell, M., Goonewardene, L., Casey, L.M., Letourneau, N., Martin, J.W., 2014. The Alberta Pregnancy Outcomes and Nutrition (APrON) cohort study: rationale and methods. Maternal Child Nutr. 10, 44-60.

Kramer, M.S., 2010. Breast is best": the evidence. Early Hum. Dev. 86, 729-732.

Kramer, M.S., Aboud, F., Mironova, E., Vanilovich, I., Platt, R.W., Matush, L., Igumnov, S., Fombonne, E., Bogdanovich, N., Ducruet, T., Collet, J.-P., Chalmers, B., Hodnett, E., Davidovsky, S., Skugarevsky, O., Trofimovich, O., Kozlova, L., Shapiro, S., 2008. Breastfeed. Child Cognit. Dev. 65, 578-584.

Krogsrud, S.K., Fjell, A.M., Tamnes, C.K., Grydeland, H., Mork, L., Due-Tønnessen, P., Bjørnerud, A., Sampaio-Baptista, C., Andersson, J., Johansen-Berg, H., Walhovd, K.B., 2016. Changes in white matter microstructure in the developing brain-A longitudinal diffusion tensor imaging study of children from 4 to 11years of age. NeuroImage 124, 473-486.

Krol, K.M., Grossmann, T., 2018. Psychological effects of breastfeeding on children and mothers. Bundesgesundheitsblatt - Gesundheitsforschung - Gesundheitsschutz 61 , 977-985.

Lebel, C., Gee, M., Camicioli, R., Wieler, M., Martin, W., Beaulieu, C., 2012. Diffusion tensor imaging of white matter tract evolution over the lifespan. NeuroImage 60, 340-352.

Lebel, C., Walker, L., Leemans, A., Phillips, L., Beaulieu, C., 2008. Microstructural maturation of the human brain from childhood to adulthood. NeuroImage 40, 1044-1055.

Leemans, A., Jeurissen, B., Sijbers, J., Jones, D., 2009. ExploreDTI: a graphical toolbox for processing, analyzing, and visualizing diffusion MR data. In: Proceedings 17th Scientific Meeting, International Society for Magnetic Resonance in Medicine, 17, p. 3537.

Luby, J.L., Belden, A.C., Whalen, D., Harms, M.P., Barch, D.M., 2016. Breastfeeding and childhood IQ: the mediating role of gray matter volume. J. Am. Acad. Child Adolesc. Psychiatry 55, 367-375.

Lugo-gil, A.J., Tamis-lemonda, C.S., Development, C., August, J., Jerald, J., Kresh, E., 2008. Family resources and parenting quality: links to children 's cognitive development across the first 3 years. 79, 1065-1085.

Martin, C., Ling, P.-R., Blackburn, G., 2016. Review of infant feeding: key features of breast milk and infant formula. Nutrients 8, 279.

Martin, CR., Ling, P-R., Blackburn, GL., 2016. Review of Infant Feeding: Key Features of Breast Milk and Infant Formula. Nutrients 8 (5), 279. doi:10.3390/nu8050279.

McCrory, C., Murray, A., 2013. The effect of breastfeeding on neuro-development in infancy. Maternal Child Health J. 17, 1680-1688.

McInerny, T.K., 2014. Breastfeeding, early brain development, and epigenetics—getting children off to their best start. Breastfeed. Med. 9, 333-334.

Michels, K.A., Ghassabian, A., Mumford, S.L., Sundaram, R., Bell, E.M., Bello, S.C., Yeung, E.H., 2017. Breastfeeding and motor development in term and preterm infants in a longitudinal US cohort. 1456-1462.

Noble, K.G., Ph, D., Houston, S.M., Brito, N.H., Ph, D., Bartsch, H., Ph, D., Kan, E., Kuperman, J.M., Ph, D., Ph, D., Amaral, D.G., Ph, D., Bloss, C.S., Ph, D., Libiger, O., 2015 Family income, parental education and brain structure in children and adolescents. $18,773-778$ 
Oddy, W.H., Kendall, G.E., Li, J., Jacoby, P., Robinson, M., de Klerk, N.H., Silburn, S.R., Zubrick, S.R., Landau, L.I., Stanley, F.J., 2010. The long-term effects of breastfeeding on child and adolescent mental health: a pregnancy cohort study followed for 14 years. J. Pediatr. 156, 568-574.

Olson, I.R., Heide, R.J.V.D., Alm, K.H., Vyas, G., 2015. Development of the uncinate fasciculus: implications for theory and developmental disorders. Dev. Cognit. Neurosci. $14,50-61$.

Oshida, K., Shimizu, T., Takase, M., Tamura, Y., Shimizu, T., Yamashiro, Y., 2003. Effects of Dietary Sphingomyelin on Central Nervous System Myelination in Developing Rats. Pediatric Research 53 (4), 589-593. doi:10.1203/01.PDR.0000054654.73826.AC.

Ou, X., Andres, A., Cleves, M.A., Pivik, R.T., Snow, J.H., Ding, Z., Badger, T.M., 2014. Sex-specific association between infant diet and white matter integrity in 8-y-old children. Pediatr. Res. 76, 535-543.

Pfefferbaum, A., Mathalon, D.H., Sullivan, E.V., Rawles, J.M., Zipursky, R.B., Lim, K.O., 1994. A quantitative magnetic resonance imaging study of changes in brain morphology from infancy to late adulthood. JAMA Neurol. 51, 874-887.

Reynolds, J., Long, X., Dmitrii, P., Bagshawe, M., Dewey, D., Lebel, C., 2020. Calgary preschool MRI dataset.

Reynolds, J.E., Grohs, M.N., Dewey, D., Lebel, C., 2019. Global and regional white matter development in early childhood. NeuroImage 196, 49-58.

Ronfani, L., Vecchi Brumatti, L., Mariuz, M., Tognin, V., Bin, M., Ferluga, V., Knowles, A., Montico, M., Barbone, F., 2015. The complex interaction between home environment, socioeconomic status, maternal IQ and early child neurocognitive development: a multivariate analysis of data collected in a newborn cohort study. PLoS One 10,1-13.

Saher, G., Brügger, B., Lappe-Siefke, C., Möbius, W., Tozawa, RI., Wehr, MC., Wieland, F., Ishibashi, S., Nave, KA., 2005. High cholesterol level is essential for myelin membrane growth. Nature Neuroscience 8 (4), 468-475. doi:10.1038/nn1426.
Seunarine, K.K., Clayden, J.D., Jentschke, S., Muñoz, M., Cooper, J.M., Chadwick, M.J., Banks, T., Vargha-Khadem, F., Clark, C.A., 2015. Sexual dimorphism in white matter developmental trajectories using tract-based spatial statistics. Brain Connect. 6 , $37-47$.

Thieba, C., Frayne, A., Walton, M., Mah, A., Benischek, A., Dewey, D., Lebel, C., 2018. Factors associated with successful MRI scanning in unsedated young children. Front. Pediatr. 6, 6-8.

Tottman, A.C., Oliver, C.J., Alsweiler, J.M., Cormack, B.E., 2020. Do preterm girls need different nutrition to preterm boys? Sex-specific nutrition for the preterm infant.. Pediatr. Res..

Urger, S.E., De Bellis, M.D., Hooper, S.R., Woolley, D.P., Chen, S.D., Provenzale, J., 2015. The superior longitudinal fasciculus in typically developing children and adolescents: diffusion tensor imaging and neuropsychological correlates. J. Child Neurol. 30, 9-20.

Walfisch, A., Sermer, C., Cressman, A., Koren, G., 2013. Breast milk and cognitive development-the role of confounders: a systematic review. BMJ Open 3, e003259.

Walton, M., Dewey, D., Lebel, C., 2018. Brain white matter structure and language ability in preschool-aged children. Brain Lang. 176, 19-25.

Wang, Y., Adamson, C., Yuan, W., Altaye, M., Rajagopal, A., Byars, A.W., Holland, S.K., 2012. Sex differences in white matter development during adolescence: a DTI study. Brain Res. 1478, 1-15.

Wechsler, D., 2012. Wechsler Preschool and Primary Scale of Intelligence-Fourth Edition (WPPSI-IV). Canadian.

WHO, 2003. Global strategy for infant and young child feeding. World Health Organization (WHO), Geneva, Switzerland.

Yeo, S.S., Jang, S.H., Son, S.M., 2014. The different maturation of the corticospinal tract and corticoreticular pathway in normal brain development: diffusion tensor imaging study. Front. Hum. Neurosci. 8, 1-6. 